\title{
A HEURISTIC APPROACH FOR GREEN VEHICLE ROUTING
}

\author{
Mehmet Soysal ${ }^{1, *}$, Mustafa Çimen $^{1}$, ÇaĞRi Sel ${ }^{2}$ And Sedat Belba $\check{G}^{3}$
}

\begin{abstract}
This paper addresses a green capacitated vehicle routing problem that accounts for transportation emissions. A Dynamic Programming approach has been used to formulate the problem. Although small-sized problems can be solved by Dynamic Programming, this approach is infeasible for larger problems due to the curse of dimensionality. Therefore, we propose a Dynamic Programming based solution approach that involves the ideas of restriction, simulation and online control of parameters to solve large-sized problems. The added values of the proposed decision support tool have been shown on a small-sized base case and relatively larger problems. Performance comparisons of the proposed heuristic against other existing Dynamic Programming based solution approaches reveal its effectiveness, as in most of the instance-setting pairs, the proposed heuristic outperforms the existing ones. Accordingly, the proposed heuristic can be used as an alternative decision support tool to tackle real routing problems confronted in sustainable logistics management.
\end{abstract}

Mathematics Subject Classification. 90-08, 90B06, 90C59, 90C90.

Received January 22, 2019. Accepted September 28, 2020.

\section{INTRODUCTION}

The capacitated vehicle routing problem (CVRP) is one of the core problems at operational level logistics management. The problem deals with the distribution of goods from a central depot to a set of dispersed customers by means of a fleet of capacitated vehicles. Each vehicle route starts and ends at the depot without exceeding the capacity of the vehicle at any point in time. The known customer demands must be satisfied by visiting each of them exactly once. The traditional objective for the CVRP is to determine a set of vehicle routes that minimizes the total distance travelled or total time spent $[10,12,30,31,39]$.

With increasing freight volumes due to the growing population and internationalization of markets, one of the main challenges of the logistics sector is to increase the efficiency of freight logistics $[1,3,6,16]$. Transportation energy use and resulting Greenhouse Gas (GHG) emissions are the foremost important issues that are considered while evaluating the efficiency of delivery operations $[6,22,43,45,48]$.

Increasing concerns about oil scarcity and climate change ${ }^{1}$ requires advanced methods or approaches to increase fuel usage efficiency in logistics operations. In response, the recent green Vehicle Routing Problem

Keywords. Routing, Dynamic Programming, Online control, Greenhouse Gas emissions.

1 Hacettepe University, Department of Business Administration, 06800 Beytepe, Ankara, Turkey.

2 Karabuk University, Department of Industrial Engineering, 78050 Karabuk, Turkey.

3 Ankara Hacı Bayram Veli University, Department of Business Administration, 06500 Beşevler, Ankara, Turkey.

* Corresponding author: mehmetsoysal@hacettepe.edu.tr

${ }^{1}$ European Commission Document (2009). Communication from the Commission - A sustainable future for transport: Towards an integrated, technology-led and user friendly system. http://eur-lex.europa.eu/legal-content/EN/ALL/?uri=CELEX:52009DC0279. Online accessed: July 2018. 
(VRP) literature $[5,9,17,32,34,35,47]$ has focused on having optimized sustainable logistics routes by means of using detailed fuel consumption and emission estimations.

The basic VRP is an NP-hard combinatorial optimization problem. Incorporating additional concerns such as explicit fuel consumption estimations further increases the problem complexity. The increase in complexity along with growing competition among logistics chains in practice causes a continuous need to search for better solution approaches for routing problems. Accordingly, the main motivation behind this research is to contribute to the field of logistics management by providing a promising decision support tool. The provided tool can be used for efficient operational decision making.

This paper presents a Dynamic Programming (DP) based heuristic for the green capacitated routing problem with heterogeneous arcs in terms of vehicle speed. The solution approach is able to manage several logistical key performance indicators (KPIs), such as total travelled distance, total energy use (which can be translated into emissions), total driving time, and total routing cost comprising fuel and wage costs. An emission model has been incorporated into the heuristic to estimate transportation costs and emissions more accurately and explicitly. The presented solution approach can be used to obtain close-to-optimal delivery plans for the largesized routing instances, since exponential memory and computation time requirements of a classical DP model restricts its usage in larger problems.

The rest of the paper is structured as follows. Section 2 presents a review of the relevant literature on the topic to show the contribution of the research. Section 3 presents the formal description of the problem. Section 4 presents a mathematical formulation of the problem and the proposed solution approach. Section 5 presents computational results for the analysed problems. The last section presents conclusions and future research directions.

\section{Related Literature RevieW}

Scholars addressing the green VRP literature regard transportation energy use and GHG emissions as prominent logistical environmental issues (see, for instance, $[13,36-38,46,48]$ ). The common goal of all of these attempts on routing problems is to improve the sustainability performance of logistics systems by means of the developed decision support models that can address the concerns for energy use and consequently emissions, while also adhering to economic concerns [21].

The featured green VRP models (see $[4,18,19,27,33]$ ) estimate transportation energy use and emissions explicitly through using several comprehensive fuel estimation approaches that take multiple aspects into account such as travelled distance, vehicle load and speed, vehicle characteristics, etc. These studies report the benefits of enhancing green VRP models through accounting for explicit transportation energy use. As discussed in Soysal [41], enhancement of the green VRP models through explicit energy estimation can enable several opportunities such as; (i) reducing relevant operational costs due to more accurate fuel consumption estimation, (ii) planning logistics operations according to the environmental and social objectives and (iii) revealing the trade-off relationships among logistics cost, transportation energy use and emissions. An interested reader on the topic can be referred to the review of recent research on green road freight transportation conducted by Demir et al. [15].

Various solution approaches and techniques (e.g., approximate dynamic programming, genetic algorithms, dynamic programming based heuristics, etc.) have been developed for Vehicle Routing Problems (VRPs) to solve large-sized problems. This research focuses on the recent DP based heuristics existing in the literature. These DP based solution approaches are highly flexible frameworks in terms of incorporating various real-life restrictions that have been generally ignored in classical vehicle routing models, such as time-dependent travel times, driving hour regulations, explicit energy use estimation [25,42]. We do believe that there is a need for research on development of DP based heuristics as routing problems are getting more complex in terms of considering new practical concerns and, in return, these approaches have the potential to handle this complexity. This study contributes to the green VRP literature by proposing a DP based heuristic for the addressed problem. 
The classical Restricted Dynamic Programming (RDP) heuristic, which is one of the earlier attempts of developing DP based heuristics, implements the idea of retaining only the limited amount of promising $(H$ most promising) partial tours at each stage of the DP algorithm. This means that every partial path that may lead to an optimal solution is not retained at each stage. The main benefit from the use of this approach is the fact that the exponential explosion of time and memory requirements of the DP algorithm is avoided. However, this heuristic does not guarantee optimality, as the states leading to the optimal solution might be pruned earlier. Gromicho et al. [24,25]; Kok et al. [28,29] present the applicability of the classical RDP heuristic to different variants of VRPs by restricting the state space in this way.

The study of Soysal and Çimen [42] and Soysal et al. [44] present another attempt on developing a DP based solution approach, Simulation-Based Restricted Dynamic Programming (SRDP), which is based on weighted random sampling, the classical RDP heuristic and simulation. They propose a different way from the previous attempts for restricting the state space in the DP algorithm. Their expansion approach suggests to select $S$ partial tours using weighted random sampling in addition to the most $H$ promising partial tours at each stage. Afterwards, the best feasible solution for the problem is found through an implemented simulation. The numerical results show that their solution approach can provide promising results within relatively short computation times compared to the classical RDP heuristic.

In this study, we propose a new approach which employs the idea of controlling and updating several key parameters of the algorithm online. This online control enables a better exploration of state space in addition to benefiting from the simulation approach to test different partial tours that may result in improved solutions for routing instances. Alternative promising feasible delivery plans provided by means of the proposed solution approach, namely Restricted Dynamic Programming with Simulation and Online Control (RDP-SOC) can be used by decision makers who are responsible for logistics operations management. We present in what follows the formal description of the problem.

\section{Problem Description}

The problem at hand is defined on a complete directed graph $G=\{V, A\}$, where $V=\{0,1, \ldots, n\}$ is the node set and $A$ is the arc set. Nodes $i \in V \backslash\{0\}$ correspond to customers, whereas node 0 corresponds to a central depot/warehouse. A set of $m$ homogeneous vehicles, each of which has the capacity of $Q$, is available at the warehouse to make the deliveries to the customers. Each customer has a known nonnegative demand, $q_{i}$, to be satisfied and a service time, $h_{i}$. After the service is completed, vehicles leave the nodes without additional waiting. Arcs $(i, j) \in A$ might be heterogeneous in terms of vehicle speed, i.e., average vehicle speeds may vary among arcs. The reason is that some arcs might have multiple road segments in different lengths (distances) and the speed of the vehicle can change according to the road section's traffic congestion and traffic regulations (see, $[2])$.

The defined problem aims to determine the routes for all vehicles, starting and ending at the warehouse, by respecting the aforementioned assumptions so as to minimize the total cost of delivery operations that includes fuel consumption cost and driver cost. The travel cost between two nodes $i \neq j \in V$ is denoted by $c_{i, j}$. The driver of each vehicle is paid from the beginning of the time horizon until returning back to the depot. Fuel consumption is dependent on travelled distance, vehicle speed and vehicle characteristics.

We employ a methodology for the estimation of ultimate $\mathrm{CO}_{2}$ emissions from road transportation operations [8]. According to that approach, the total amount of transportation emissions $E(\mathrm{~g} / \mathrm{km})$ generated for traversing one $\mathrm{km}$ at a constant speed $v(\mathrm{~km} / \mathrm{h})$ is calculated as follows:

$$
E=\frac{k\left(a+b v+c v^{2}+d v^{3}+e v^{4}+f v^{5}+g v^{6}\right)}{v}
$$

where $k, a, b, c, d, e, f$ and $g$ are vehicle specific parameters. The reader is referred to the technical report of Boulter et al. [8] for further details on these parameters. After estimating emission levels, we estimate corresponding fuel consumption amounts by using a fuel conversion factor for transport activities. 


\section{The SOlution APPROACH}

This section first describes the DP algorithm for the addressed problem, then introduces a solution approach.

\subsection{Dynamic Programming model}

We employ a DP algorithm methodology based on the DP formulation introduced by Bellman [7] and Held and Karp [26] for the Traveling Salesman Problem (TSP). Given a network, the TSP aims to find the shortest possible route that visits each city exactly once and returns to the starting point. The addressed green routing problem is first transformed into the TSP by means of a giant-tour representation, which was introduced by Funke et al. [20], then the DP algorithm is used to formulate and solve the problem.

The DP algorithm of the TSP calculates the routes for each vehicle subsequently, which means that there exists only one vehicle called active vehicle whose route is being calculated at any point in time. This allows the algorithm to track the information on vehicle load and time (see, $[24,25,29])$. Load tracking enables to respect the vehicle capacities and time tracking enables to calculate driver cost. Algorithm 1 presents the DP algorithm for the addressed problem.

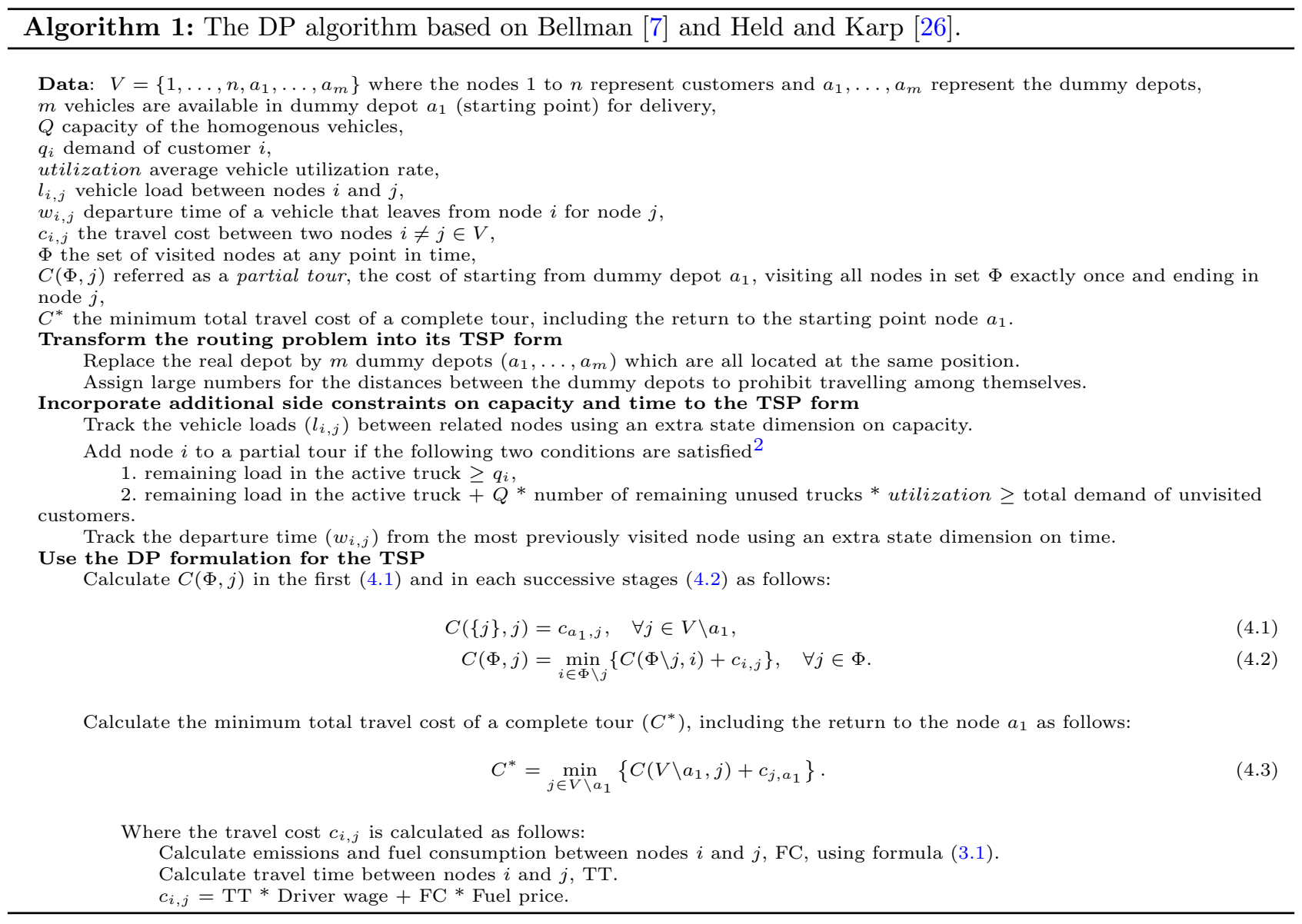

\footnotetext{
${ }^{2}$ The first condition ensures that the vehicle visits a node, if it has sufficient load to satisfy the demand. The second condition restricts vehicles to visit dummy depots with low utilization rates by taking idle capacity of vehicles into account [42].
} 


\subsection{Restricted dynamic programming with simulation and online control}

The described DP algorithm is infeasible for the larger routing problems due to enormous computational burden and time requirements. In response, we propose a DP based heuristic algorithm in order to obtain promising results for larger problems within short computation times. The introduced approach involves the ideas of restriction, simulation and online control of parameters.

In what follows, we summarize the RDP-SOC heuristic and provide the necessary steps at each stage of the algorithm:

- List all potential partial tours. Eliminate any unpromising ones online, based on whether their current cost-to-go values allude to a higher cost of a complete tour than that of the best solution found so far.

- Sort a predefined number of the remaining partial tours, and normalize their cost-to-go values.

- Select $M$ most promising partial tours. $M$ is restricted by two parameters updated online at the beginning of each simulation iteration. First, normalized cost-to-go values of any selected partial tours cannot exceed a random rate. Second, $M$ cannot exceed the randomly defined quota of partial tours expanded in each stage $(\hat{H})$.

- If the quota $(\hat{H})$ is not filled, select the remaining $\hat{H}-M$ partial tours according to assigned probabilities with respect to their cost-to-go values, using weighted random sampling.

- Keep track of the selected $\hat{H}$ partial tours in the next stage, until all nodes are visited.

Our heuristic suggests to (i) restrict the number of tracked partial tours in each stage (see, $[24,25,28,29]$ ), (ii) use a simulation to try different partial tours that may result in an improved solution (see, [42]), and (iii) control and update key parameters online that enables a better exploration of state space.

To implement the RDP-SOC heuristic, the necessary steps at each stage of the DP algorithm are presented in detail in Algorithm 2. Since RDP-SOC involves random number generation and simulation processes, each run of the algorithm will yield different solutions even for the same problem. A fair performance assessment can be performed by means of a Monte Carlo simulation (e.g., see Algorithm 3).

The recursion requires a proper state space exploration to find close-to-optimal feasible solutions. As distinct from the existing DP based solution approaches, the proposed heuristic introduced above benefits from online control of key parameters that enables to find out promising state space expansion. The potential benefits that could be obtained from the use of the introduced solution approach are investigated in the following section.

\section{NuMERICAL EXPERIMENTATION}

This section first aims to show the applicability of RDP-SOC on a base case. Then, the performance of the proposed heuristic has been assessed against the classical RDP and SRDP heuristics using the base case, two additional small-sized problems and nine problems that are relatively larger in size.

DP based solution algorithms here for the conducted experiments have been developed using $\mathrm{C}++$ programming language. We have used a computer of Pentium(R) i7-7700 K 4.2 GHz CPU with 8 GB memory.

\subsection{Base case analyses}

We first describe the addressed problem referred to as the base case and present the corresponding data used. The following seven logistical KPIs have been used for the evaluation of the resultant policies: (i) number of vehicles used, (ii) total travelled distance, (iii) total emissions, (iv) total driving time, (v) total fuel cost, (vi) total wage cost and (vii) total routing cost [11]. 


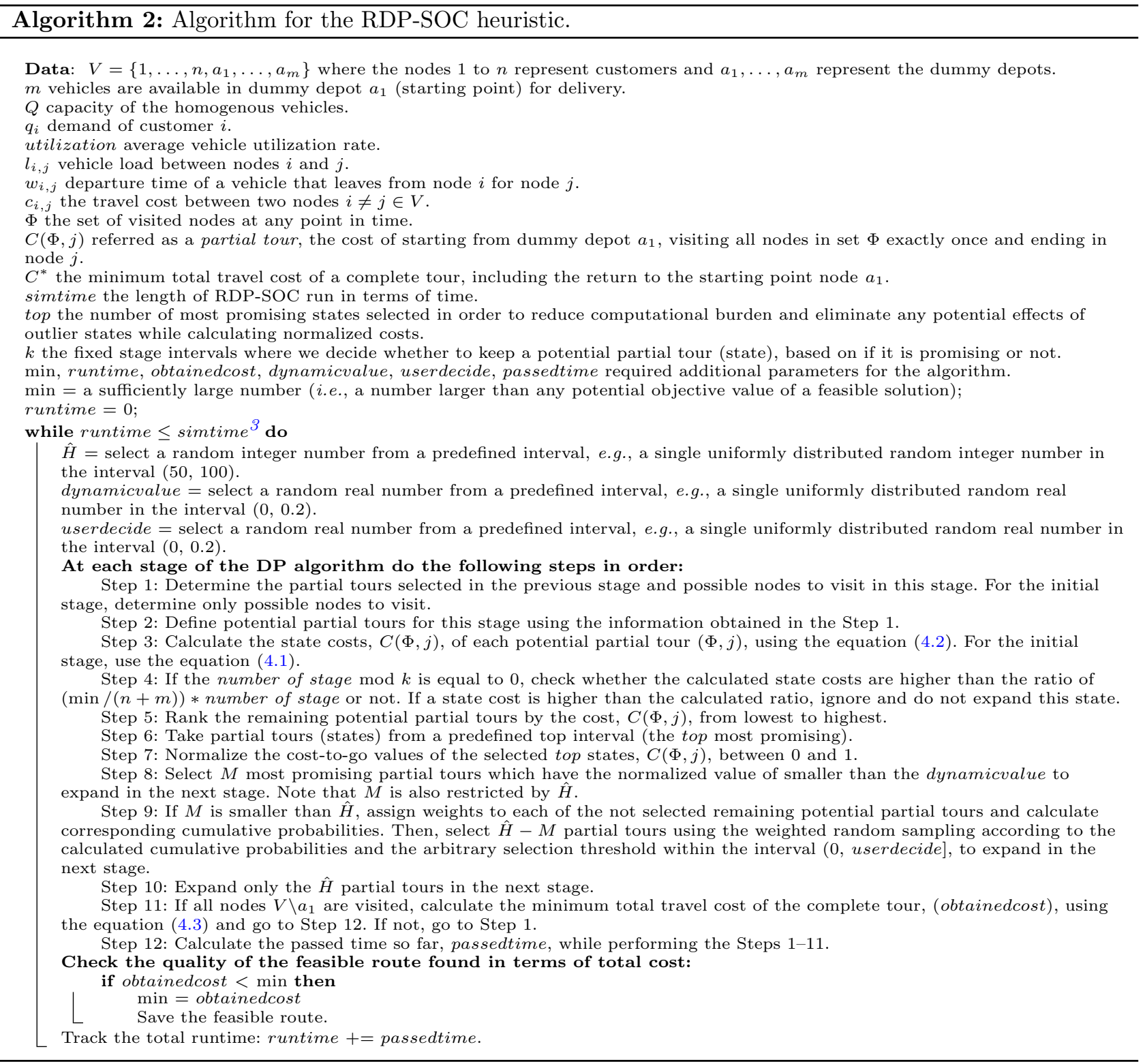

\subsubsection{Description and Data}

The data for the problem has been taken from the Pollution-Routing Problem Instance Library ${ }^{4}$ The data, which is referred to as UK15_01 in the web-site, is based on real distances collected from the chosen United Kingdom cities. The studied transportation network in our base case includes one depot located in Galashiels and 15 customers located in nearby cities, as shown in Figure 1. The name of customer locations together with customer demands and related service times can be seen from the Table 1.

\footnotetext{
${ }^{3}$ Note that since the runtime is checked only once at the beginning of this loop, the simtime can be expired before the end of the loop, which means that the final runtime may exceed simtime. The gap will always be smaller than the length of a single run of the 12 steps. At a cost of slower computation, the runtime may be checked more frequently within the loop.

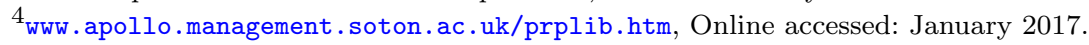



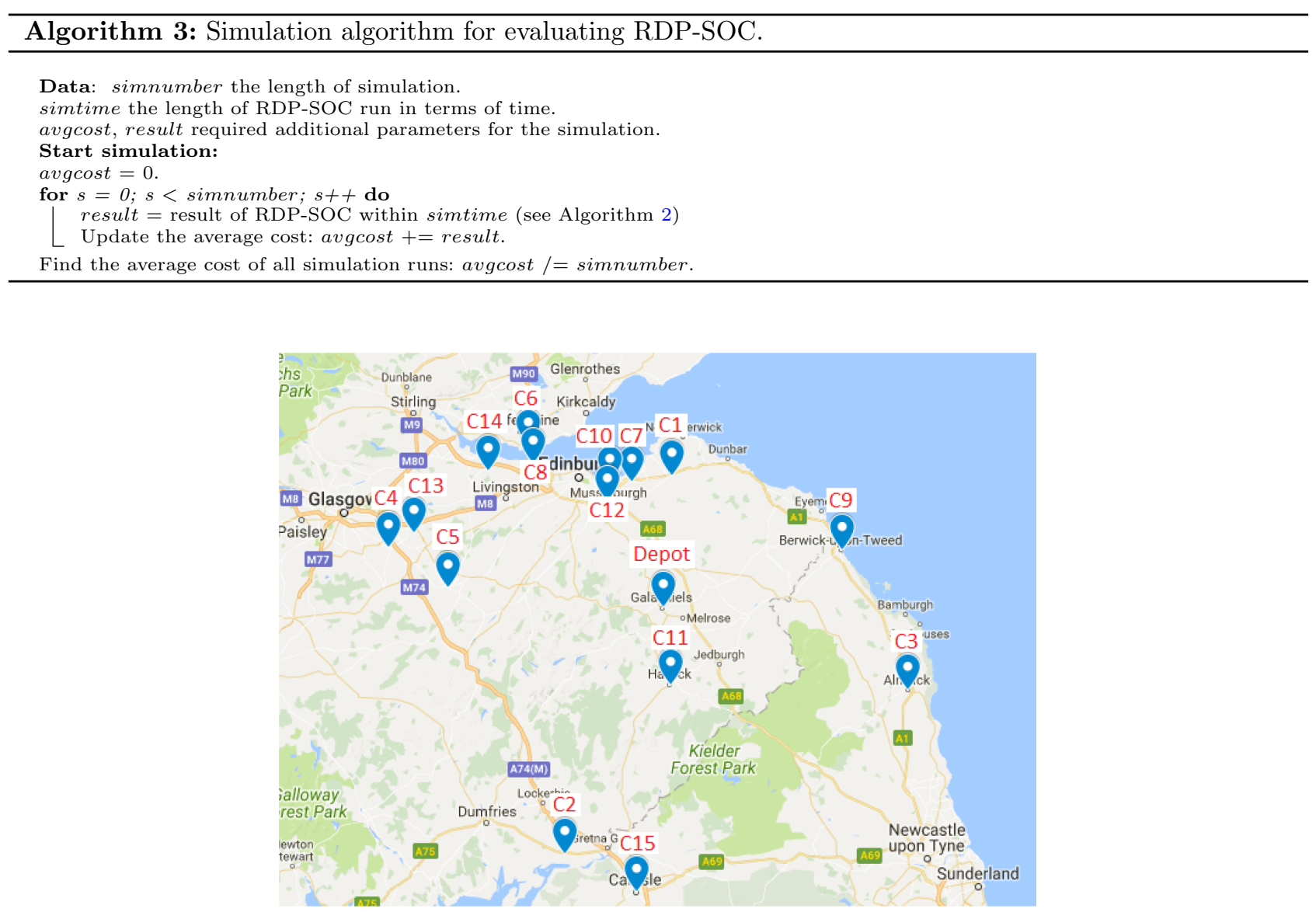

FiguRE 1. Representation of the logistics network.

Two homogeneous rigid heavy goods vehicles with a capacity of $4000 \mathrm{~kg}$ are used for the deliveries from the depot to the customers. It is assumed that vehicles consume diesel with an emission standard of Euro V. To calculate ultimate $\mathrm{CO}_{2}$ emissions, the data presented in the technical report of Boulter et al. [8] for the diesel Euro V rigid heavy goods vehicles are used. This technical report presents estimated exhaust emission factors for road vehicles in the UK. To be used in equation (3.1), required parameters are set as follows: $a=12690$, $b=16.564, c=86.867, d=-3.5532, e=0.061462, f=-0.0004773, g=0.0000013853$ and $k=1$ (see page 173 of the report [8]). The fuel conversion factor of $2.63 \mathrm{~kg} / \mathrm{l}$ has been used to estimate corresponding fuel consumption amounts [14]. Table 2 presents the distance matrix.

The average vehicle speed between the nodes under regular traffic conditions are provided from the Google $\mathrm{Maps}^{5}$. As can be seen from the matrix presented in Table 3, average speeds between the nodes vary between nearly $9 \mathrm{~m} / \mathrm{s}$ and $25 \mathrm{~m} / \mathrm{s}$.

Fuel price and wage parameters required to calculate fuel consumption and driver costs are taken as $1.6 € / 1$ and $0.004 € / \mathrm{s}$, respectively. The objective of the problem is to determine the vehicle routes that start and end at the depot and visit each customer exactly once such that the total routing cost is minimized.

\footnotetext{
${ }^{5}$ http://maps.google.com.tr/, Online accessed: January 2017.
} 
TABLE 1. Demand of customers and corresponding service times.

\begin{tabular}{lll}
\hline \hline & Demand (in kg) & Service time (in s) \\
\hline Depot - Galashiels & 0 & 0 \\
C1 - Haddington & 178 & 356 \\
C2 - Annan & 397 & 794 \\
C3 - Alnwick & 693 & 1386 \\
C4 - Hamilton & 346 & 692 \\
C5 - Lanark & 785 & 1570 \\
C6 - Rosyth & 803 & 1606 \\
C7 - Tranent & 609 & 1218 \\
C8 - Queensferry & 216 & 432 \\
C9 - Berwick-Upon-Tweed & 345 & 690 \\
C10 - Musselburgh & 748 & 1496 \\
C11 - Hawick & 473 & 946 \\
C12 - Dalkeith & 103 & 206 \\
C13 - Newarthill & 486 & 972 \\
C14 - Linlithgow & 410 & 820 \\
C15 - Carlisle & 627 & 1254 \\
\hline
\end{tabular}

TABLE 2. Distances between nodes, in meters.

\begin{tabular}{|c|c|c|c|c|c|c|c|c|c|c|c|c|c|c|c|c|}
\hline & Depot & $\mathrm{C} 1$ & $\mathrm{C} 2$ & $\mathrm{C} 3$ & $\mathrm{C} 4$ & C5 & $\mathrm{C} 6$ & $\mathrm{C} 7$ & $\mathrm{C} 8$ & $\mathrm{C} 9$ & $\mathrm{C} 10$ & $\mathrm{C} 11$ & $\mathrm{C} 12$ & $\mathrm{C} 13$ & C14 & $\mathrm{C} 15$ \\
\hline Depot & - & 50941 & 92751 & 440 & 96450 & 75910 & 76210 & 49310 & 69650 & 64640 & 49720 & 24280 & 70 & 91230 & 81440 & 94581 \\
\hline $\mathrm{C} 1$ & 51061 & - & 137773 & 103641 & 92220 & 82280 & 52100 & 15280 & 45540 & 59500 & 21230 & 72601 & 23220 & 83460 & 57960 & 142902 \\
\hline $\mathrm{C} 2$ & 92801 & 137743 & - & 140991 & 111514 & 94983 & 144893 & 132233 & 137923 & 137732 & 128923 & 69441 & 122493 & 114864 & 133533 & 31220 \\
\hline $\mathrm{C} 3$ & 90990 & 103631 & 141351 & - & 202421 & 162160 & 149801 & 115361 & 143241 & 50070 & 120501 & 89141 & 117041 & 193391 & 157061 & 118581 \\
\hline $\mathrm{C} 4$ & 96200 & 91870 & 111305 & 202802 & - & 23070 & 59960 & 79550 & 52810 & 149200 & 72530 & 115100 & 71390 & 9820 & 42090 & 135015 \\
\hline C5 & 75930 & 82130 & 94894 & 162320 & 23080 & - & 56290 & 69810 & 48910 & 135520 & 62790 & 94830 & 59680 & 20620 & 40530 & 118604 \\
\hline C6 & 76390 & 52140 & 144795 & 149631 & 60440 & 56260 & - & 39820 & 8040 & 109170 & 32800 & 100020 & 33360 & 52320 & 20600 & 166484 \\
\hline $\mathrm{C} 7$ & 49450 & 15280 & 132263 & 115381 & 79900 & 69960 & 39780 & - & 33220 & 71240 & 8910 & 73080 & 10980 & 71140 & 45640 & 143381 \\
\hline $\mathrm{C} 8$ & 69770 & 45520 & 137774 & 143011 & 53160 & 48980 & 8010 & 33200 & - & 102550 & 26180 & 93400 & 26740 & 45040 & 14050 & 159864 \\
\hline C9 & 64610 & 59100 & 137842 & 50100 & 149170 & 135780 & 108720 & 70830 & 10 & - & 77850 & 69990 & & 140500 & 80 & 13 \\
\hline $\mathrm{C} 10$ & 49430 & 21240 & 128745 & 120011 & 72830 & 62890 & 32710 & 8920 & 26150 & 78270 & - & 73060 & 7220 & 64070 & 38570 & 143361 \\
\hline $\mathrm{C} 11$ & 24310 & 72661 & 69411 & 89141 & 115520 & 94980 & 100060 & 73160 & 93500 & 69950 & 73570 & - & 68820 & 110300 & 105290 & 71241 \\
\hline $\mathrm{C} 12$ & 45090 & 23200 & 122215 & 116961 & 71200 & 59800 & 33450 & 11010 & 26890 & 78940 & 7130 & 68720 & - & 62170 & 39310 & 139021 \\
\hline $\mathrm{C} 13$ & 91250 & 83700 & 114645 & 193972 & 10310 & 20630 & 52340 & 71380 & 45190 & 140810 & 64360 & 110150 & 62560 & - & 34470 & 138355 \\
\hline $\mathrm{C} 14$ & 81960 & 58010 & 133314 & 156841 & 42450 & 40610 & 20380 & 45690 & 14140 & 115040 & 38670 & 105590 & 39230 & 34330 & - & 157024 \\
\hline $\mathrm{C} 15$ & 94731 & 143082 & 30970 & 118401 & 135135 & 118604 & 166424 & 143581 & 159864 & 135381 & 143991 & 71371 & 139241 & 138485 & 157 & - \\
\hline
\end{tabular}

\subsubsection{Base case solution}

The DP model provides the optimal vehicle routes for the introduced problem within approximately two hours. Summary results which show the performance of the resulting delivery plan in terms of the defined KPIs are presented in Table 4. As can be seen from this table, sustainable logistics decision makers have a chance to track both economic (logistics cost) and environmental (emitted emissions, driving time) performances of the delivery plans provided from the use of the DP model.

Table 5 presents the detailed representation of the resulting delivery plan broken down into each travelled arc. Here, we would like to note that the DP model for the addressed problem regards the imposed average speeds at each arc. Using realistic speed data allows the model to better estimate travel time, fuel consumption (emitted emissions), and therefore resulting logistics cost. Another remark is that both of the available vehicles are employed to satisfy the customer demands. The utilization rates for the first and second vehicles are $97.4 \%$ and $83.1 \%$, respectively. 
TABLE 3. Average vehicle speeds between nodes, in $\mathrm{m} / \mathrm{s}$.

\begin{tabular}{llllllllllllllllll}
\hline \hline & Depot & C1 & C2 & C3 & C4 & C5 & C6 & C7 & C8 & C9 & C10 & C11 & C12 & C13 & C14 & C15 \\
\hline Depot & & 16.33 & 16.99 & 16.93 & 17.66 & 16.22 & 18.41 & 18.26 & 17.86 & 16.83 & 17.63 & 13.49 & 17.85 & 18.77 & 19.39 & 16.42 \\
C1 & 16.37 & - & 19.79 & 21.87 & 22.94 & 19.31 & 19.30 & 25.47 & 18.51 & 23.06 & 20.81 & 16.35 & 19.35 & 24.40 & 21.00 & 14.61 \\
C2 & 17.00 & 19.62 & - & 19.58 & 25.81 & 22.94 & 20.82 & 20.04 & 20.34 & 18.36 & 21.70 & 18.67 & 21.27 & 23.93 & 22.48 & 15.77 \\
C3 & 16.66 & 21.59 & 19.47 & - & 23.27 & 18.14 & 20.30 & 22.10 & 20.23 & 21.96 & 21.37 & 16.51 & 20.11 & 23.88 & 21.28 & 19.19 \\
C4 & 17.06 & 22.19 & 25.41 & 23.31 & - & 13.26 & 18.86 & 21.04 & 17.96 & 22.61 & 19.50 & 16.12 & 20.51 & 9.63 & 15.25 & 25.00 \\
C5 & 16.22 & 19.28 & 22.59 & 18.40 & 13.74 & - & 16.75 & 18.18 & 15.98 & 20.17 & 16.35 & 16.13 & 16.86 & 13.22 & 14.68 & 22.72 \\
C6 & 18.45 & 19.31 & 20.98 & 20.61 & 19.37 & 17.05 & - & 17.46 & 12.18 & 21.16 & 14.39 & 17.01 & 16.35 & 20.76 & 13.73 & 21.02 \\
C7 & 17.54 & 25.47 & 20.04 & 22.36 & 21.83 & 17.94 & 17.00 & - & 15.82 & 23.28 & 13.50 & 16.68 & 14.08 & 23.25 & 19.50 & 18.82 \\
C8 & 17.89 & 18.50 & 20.69 & 20.37 & 18.85 & 16.01 & 12.14 & 16.27 & - & 20.84 & 12.83 & 16.56 & 15.37 & 20.29 & 11.15 & 20.82 \\
C9 & 16.83 & 21.89 & 18.23 & 22.57 & 22.81 & 19.85 & 20.83 & 22.70 & 20.51 & - & 21.99 & 18.23 & 21.12 & 23.65 & 21.70 & 17.22 \\
C10 & 17.91 & 20.82 & 19.69 & 21.51 & 20.23 & 16.38 & 14.35 & 16.52 & 12.82 & 22.49 & - & 16.91 & 10.03 & 21.36 & 16.92 & 18.96 \\
C11 & 13.97 & 16.59 & 18.36 & 17.08 & 16.18 & 16.32 & 17.19 & 17.17 & 16.94 & 18.80 & 17.03 & - & 16.87 & 16.87 & 18.09 & 17.46 \\
C12 & 17.89 & 19.33 & 19.40 & 20.31 & 21.19 & 16.61 & 16.40 & 13.11 & 14.94 & 21.22 & 9.90 & 16.36 & - & 22.53 & 18.72 & 18.99 \\
C13 & 19.01 & 24.91 & 23.59 & 24.49 & 9.04 & 13.22 & 21.81 & 24.28 & 21.52 & 24.19 & 22.35 & 16.84 & 23.70 & - & 17.95 & 23.53 \\
C14 & 19.24 & 21.02 & 20.20 & 21.43 & 15.72 & 14.40 & 14.15 & 19.53 & 11.78 & 22.04 & 16.53 & 17.78 & 18.68 & 16.35 & - & 20.61 \\
C15 & 17.16 & 18.34 & 17.80 & 18.97 & 26.19 & 23.82 & 21.34 & 19.30 & 20.98 & 17.77 & 19.51 & 18.30 & 19.34 & 24.55 & 21.29 & - \\
\hline
\end{tabular}

TABLE 4. Summary results for the base case.

\begin{tabular}{ll}
\hline \hline KPIs & Results \\
\hline \# of vehicles used & 2 \\
Total travelled distance $(\mathrm{km})$ & 667.68 \\
Total emissions $(\mathrm{kg})$ & 558.76 \\
Total driving time $(\mathrm{h})$ & 14.61 \\
Total fuel cost $(€)$ & 339.93 \\
Total wage cost $(€)$ & 210.39 \\
Total routing cost $(€)$ & 550.32 \\
\hline
\end{tabular}

TABLE 5. Representation of the resulting delivery plan for the base case.

\begin{tabular}{|c|c|c|c|c|c|c|c|}
\hline & Arc & Distance $(\mathrm{m})$ & Speed $(\mathrm{m} / \mathrm{s})$ & Travel time (s) & Service time $(\mathrm{s})$ & Emissions (kg) & Fuel consumption (l) \\
\hline \multirow{9}{*}{ 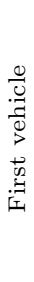 } & Depot-C5 & 75910 & 16.22 & 4680 & 1570 & 62.20 & 23.65 \\
\hline & $\mathrm{C} 5-\mathrm{C} 4$ & 23080 & 13.74 & 1680 & 692 & 20.03 & 7.61 \\
\hline & C4-C13 & 9820 & 9.63 & 1020 & 972 & 10.45 & 3.98 \\
\hline & $\mathrm{C} 13-\mathrm{C} 14$ & 34470 & 17.95 & 1920 & 820 & 27.99 & 10.64 \\
\hline & $\mathrm{C} 14-\mathrm{C} 6$ & 20380 & 14.15 & 1440 & 1606 & 17.45 & 6.63 \\
\hline & C6-C8 & 8040 & 12.18 & 660 & 432 & 7.44 & 2.83 \\
\hline & C8-C10 & 26180 & 12.83 & 2040 & 1496 & 23.52 & 8.94 \\
\hline & $\mathrm{C} 10-\mathrm{C} 12$ & 7220 & 10.03 & 720 & 206 & 7.50 & 2.85 \\
\hline & C12-Depot & 45090 & 17.89 & 2520 & 0 & 36.61 & 13.92 \\
\hline \multirow{9}{*}{ 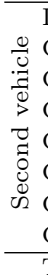 } & Depot-C7 & 49310 & 18.26 & 2700 & 1218 & 40.06 & 15.23 \\
\hline & $\mathrm{C} 7-\mathrm{C} 1$ & 15280 & 25.47 & 600 & 356 & 13.26 & 5.04 \\
\hline & $\mathrm{C} 1-\mathrm{C} 9$ & 59500 & 23.06 & 2580 & 690 & 50.55 & 19.22 \\
\hline & $\mathrm{C} 9-\mathrm{C} 3$ & 50100 & 22.57 & 2220 & 1386 & 42.34 & 16.10 \\
\hline & C3-C15 & 118581 & 19.19 & 6180 & 1254 & 96.77 & 36.80 \\
\hline & C15-C2 & 30970 & 17.80 & 1740 & 794 & 25.15 & 9.56 \\
\hline & $\mathrm{C} 2-\mathrm{C} 11$ & 69441 & 18.67 & 3720 & 946 & 56.50 & 21.48 \\
\hline & C11-Depot & 24310 & 13.97 & 1740 & 0 & 20.93 & 7.96 \\
\hline & Total & 667682 & & 38160 & 14438 & 558.76 & 212.46 \\
\hline
\end{tabular}


TABLE 6. Parameter settings used for the solution approaches.

\begin{tabular}{|c|c|c|c|c|c|}
\hline \multirow[b]{2}{*}{ Problem } & \multirow[b]{2}{*}{ Parameter* } & \multicolumn{4}{|c|}{ Solution approaches } \\
\hline & & $\mathrm{DP}$ & RDP & SRDP & RDP-SOC \\
\hline BC, SIs, LIs** & simnumber & - & - & 30 & 30 \\
\hline BC, SIs, LIs & utilization & 0.9 & 0.9 & 0.9 & 0.9 \\
\hline BC, SIs, LIs & $H$ & - & $\begin{array}{l}50,100,250, \\
500,1000,2500\end{array}$ & - & - \\
\hline BC, SIs & & - & - & 70 and 30 & - \\
\hline LIs & $H$ and $S$ & - & - & 7 and 3 & - \\
\hline $\mathrm{BC}, \mathrm{SIs}$ & & - & - & - & Uniform $^{* * *}(50,100)$, integer \\
\hline LIs & $H$ & - & - & - & Uniform $(5,10)$, integer \\
\hline BC, SIs, LIs & dynamicvalue & - & - & - & Uniform $(0,0.2)$, real number \\
\hline $\mathrm{BC}, \mathrm{SIs}, \mathrm{LIs}$ & userdecide & - & - & 0.1 & Uniform $(0,0.5)$, real number \\
\hline BC, SIs, LIs & $k$ & - & - & - & 5 \\
\hline $\mathrm{BC}, \mathrm{SIs}$ & & - & - & - & 1000 \\
\hline LIs & top & - & - & - & 100 \\
\hline
\end{tabular}

Notes. ${ }^{*}$ See Algorithm 2 for the notation meaning. ${ }^{* *} \mathrm{BC}$ refers base case, SIs refers smaller problems, LIs refers larger problems. ${ }^{* * *} \mathrm{~A}$ single uniformly distributed random number in the given interval.

\subsection{Heuristic performance assessment}

This subsection aims to assess the performance of the RDP-SOC heuristic by means of the base case, two small-sized problems and a set of larger problems. In the analyses on the base case and small-sized problems, the performance of the proposed heuristic is compared against the optimal policy provided by the DP algorithm and the feasible policies provided by the classical RDP algorithm (see, [24, 25, 28, 29]) and SRDP heuristic [42]. Due to curse of dimensionality, the DP algorithm is infeasible for the larger problems [11]. Therefore, the optimal policies for these problems cannot be calculated by the DP approach. Accordingly, to assess the performance of the RDP-SOC heuristic on the larger problems, feasible solutions which are obtained from the classical RDP and SRDP solution approaches are used. Table 6 presents the parameter settings used for the solution approaches in our computational analyses.

\subsubsection{Heuristic applied to base case}

This subsection presents the performances of the classical RDP, SRDP and RDP-SOC heuristics on the base case. While defining the time limits (see the required parameter simtime in Algorithm 2) for a single run of the SRDP and RDP-SOC heuristics, the observed computation times of the classical RDP algorithm have been used. Table 7 presents the comparison results.

According to the results, for instances 5 and 6 , the classical RDP heuristic is able to find optimal solution for the base case, which is $€ 550.32$ as presented in Table 4. Although the solution approaches SRDP and RDP-SOC could not obtain the optimal policy, they achieved to provide near-optimal solutions for the base case. Another remark is that the proposed heuristic has slightly outperformed the SRDP heuristic in terms of the average cost. The following subsection provides additional comparison analyses among the aforementioned heuristics on small-sized problems.

\subsubsection{Heuristic applied to small-sized problems}

This subsection presents the performances of the classical RDP, SRDP and RDP-SOC heuristics on the two additional small-sized problems. These small-sized problems have been obtained from The Pollution-Routing Problem Instance Library ${ }^{6}$. The first problem (UK10_01) has a single depot and 10 customers, whereas the

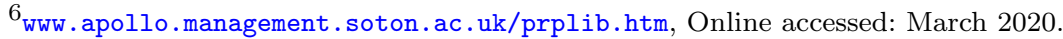


TABle 7. Performance assessment of the classical RDP, SRDP and RDP-SOC heuristics on the base case.

\begin{tabular}{|c|c|c|c|c|c|c|c|c|c|}
\hline \multirow[b]{2}{*}{$\#$} & \multicolumn{3}{|c|}{ Classical RDP } & \multicolumn{3}{|c|}{ SRDP } & \multicolumn{3}{|c|}{ RDP-SOC } \\
\hline & Setting & Cost $(€)$ & $\begin{array}{l}\text { Comp. } \\
\text { Time (s) }\end{array}$ & Setting & $\begin{array}{l}\text { Avg. } \\
\text { Cost }(€)\end{array}$ & $\begin{array}{l}\text { Avg. Comp. } \\
\text { Time (s) }\end{array}$ & Setting & $\begin{array}{l}\text { Avg. } \\
\text { Cost }(€)\end{array}$ & $\begin{array}{l}\text { Avg. Comp. } \\
\text { Time (s) }\end{array}$ \\
\hline 1 & $H=50$ & 553.01 & 1 & $H=70, S=30$ & 553.01 & 1 & $50 \leq \hat{H} \leq 100$ & 553.01 & 1 \\
\hline 2 & $H=100$ & 553.01 & 1 & $H=70, S=30$ & 553.01 & 1 & $50 \leq \hat{H} \leq 100$ & 553.01 & 1 \\
\hline 3 & $H=250$ & 553.01 & 2 & $H=70, S=30$ & 553.01 & 3 & $50 \leq \hat{H} \leq 100$ & 553.01 & 3 \\
\hline 4 & $H=500$ & 550.47 & 4 & $H=70, S=30$ & 553.01 & 4 & $50 \leq \hat{H} \leq 100$ & 553.01 & 4 \\
\hline 5 & $H=1000$ & 550.32 & 12 & $H=70, S=30$ & 553.01 & 12 & $50 \leq \hat{H} \leq 100$ & 552.91 & 12 \\
\hline 6 & $H=2500$ & 550.32 & 64 & $H=70, S=30$ & 553.01 & 64 & $50 \leq \hat{H} \leq 100$ & 552.69 & 64 \\
\hline
\end{tabular}

Notes. Bold values demonstrate the relatively better results.

TABLE 8. Performance assessment of the classical RDP, SRDP and RDP-SOC heuristics on the small-sized problems.

\begin{tabular}{|c|c|c|c|c|c|c|c|c|c|c|}
\hline \multirow[b]{2}{*}{ Instances } & \multirow[b]{2}{*}{ \# } & \multicolumn{3}{|c|}{ Classical RDP } & \multicolumn{3}{|c|}{ SRDP } & \multicolumn{3}{|c|}{ RDP-SOC } \\
\hline & & Setting & Cost $(€)$ & $\begin{array}{l}\text { Comp. } \\
\text { Time (s) }\end{array}$ & Setting & $\begin{array}{c}\text { Avg. } \\
\text { Cost }(€)\end{array}$ & $\begin{array}{l}\text { Avg. Comp. } \\
\text { Time (s }\end{array}$ & Setting & $\begin{array}{c}\text { Avg. } \\
\text { Cost }(€)\end{array}$ & $\begin{array}{l}\text { Avg. Comp. } \\
\text { Time (s) }\end{array}$ \\
\hline \multirow{6}{*}{ 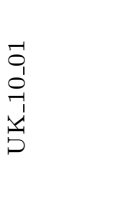 } & 1 & $H=50$ & 332.77 & 1 & $H=70, S=30$ & 332.77 & 1 & $50 \leq \hat{H} \leq 100$ & 325.98 & 1 \\
\hline & 2 & $H=100$ & 332.77 & 1 & $H=70, S=30$ & 332.77 & 1 & $50 \leq \hat{H} \leq 100$ & 325.98 & 1 \\
\hline & 3 & $H=250$ & 325.41 & 2 & $H=70, S=30$ & 332.77 & 2 & $50 \leq \hat{H} \leq 100$ & 325.59 & 2 \\
\hline & 4 & $H=500$ & 325.41 & 3 & $H=70, S=30$ & 332.77 & 3 & $50 \leq \hat{H} \leq 100$ & 325.41 & 3 \\
\hline & 5 & $H=1000$ & 325.41 & 5 & $H=70, S=30$ & 332.77 & 5 & $50<\hat{H}<100$ & 325.41 & 5 \\
\hline & 6 & $H=2500$ & 325.41 & 13 & $H=70, S=30$ & 332.77 & 13 & $50 \leq \hat{H} \leq 100$ & 325.41 & 13 \\
\hline \multirow{6}{*}{ 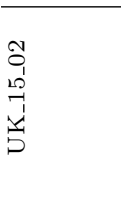 } & 1 & $H=50$ & 435.42 & 1 & $H=70, S=30$ & 435.34 & 1 & $50<\hat{H}<100$ & 435.28 & 1 \\
\hline & 2 & $H=100$ & 435.34 & 1 & $H=70, S=30$ & 435.34 & 1 & $50 \leq \hat{H} \leq 100$ & 435.28 & 1 \\
\hline & 3 & $H=250$ & 434.73 & 2 & $H=70, S=30$ & 435.34 & 2 & $50 \leq \hat{H} \leq 100$ & 435.26 & 2 \\
\hline & 4 & $H=500$ & 434.73 & 4 & $H=70, S=30$ & 435.34 & 4 & $50 \leq \hat{H} \leq 100$ & 433.35 & 4 \\
\hline & 5 & $H=1000$ & 434.73 & 12 & $H=70, S=30$ & 435.34 & 12 & $50 \leq \hat{H} \leq 100$ & 427.94 & 12 \\
\hline & 6 & $H=2500$ & 432.28 & 53 & $H=70, S=30$ & 435.34 & 53 & $50 \leq \hat{H} \leq 100$ & 418.54 & 53 \\
\hline
\end{tabular}

Notes. Bold values demonstrate the relatively better results.

second problem (UK15_02) has a single depot and 15 customers. In both problems, two homogeneous vehicles are used for the delivery operations. Vehicle capacities are assumed as 3650 and $4000 \mathrm{~kg}$ in the first and second problems, respectively. The vehicles travel at an average speed of $90 \mathrm{~km} / \mathrm{h}$ in all arcs. Other required data for the problems, i.e., distances matrix, customer demands and customer service times can be obtained from the web site of The Pollution-Routing Problem Instance Library. Table 8 presents the comparison results.

The optimal solutions provided by the classical DP algorithm for the first and second problems are $€ 325.41$ and $€ 398.29$, respectively. According to the results, RDP-SOC outperforms the SRDP heuristic in all instancesetting pairs. The performances of the proposed heuristic are also equal to or better than that of the classical RDP heuristic in 5 out of 6 instance-setting pairs for both UK_10_01 and UK_15_02 problems. Note that both the classical RDP and RDP-SOC are able to provide the optimal solution for UK_10_01. The following subsection provides more extensive performance comparison analyses among the RDP, SRDP and RDP-SOC heuristics on large-sized problems.

\subsubsection{Heuristic applied to large-sized problems}

This subsection presents the performances of the classical RDP, SRDP and RDP-SOC heuristics in relatively large problems. These large problems have been obtained from The Pollution-Routing Problem Instance Library ${ }^{7}$

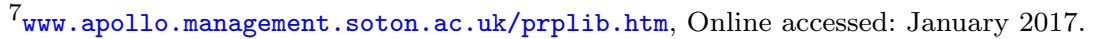


and The Routing Problem Library introduced by Solomon [40]. These libraries have been used in many other studies addressing routing problem variants (see, e.g., $[4,23]$ ).

Nine problems each of which has a single depot and 50 customers have been used for the analyses. For the delivery, (i) seven vehicles are employed in problems 1 (UK50_01), 2 (UK50_02) and 5 (UK50_05), (ii) eight vehicles are employed in problems 3 (UK50_03) and 4 (UK50_04), and (iii) four vehicles are employed in problems 6-9 (C101, C201, R101 and RC101). The vehicle capacity is taken as $3650 \mathrm{~kg}$ for problems $1-5$ and $270 \mathrm{~kg}$ for problems 6-9. Other required data for the problems, i.e., distances matrix, customer demands and customer service times can be obtained from the The Pollution-Routing Problem Instance Library and The Routing Problem Library.

The provided data does not contain any information about potential road segments as it has been prepared for the use of traditional routing models. Therefore, we assumed that all arcs have a fraction of urban and non-urban parts. The following approach has been used while defining the corresponding fractions. The arcs between odd customer numbers (e.g., between nodes-customers 1 and 3, 5 and 7 or 47 and 49) and even numbers (e.g., between nodes 2 and 4, 6 and 8 or 48 and 50) have $15 \%$ urban and $85 \%$ non-urban section. The remaining arcs (e.g., between nodes 1 and 4, 2 and 5 or 47 and 48 ) have $5 \%$ urban and $95 \%$ non-urban section. The vehicles travel at an average speed of $40 \mathrm{~km} / \mathrm{h}$ in urban sections and $90 \mathrm{~km} / \mathrm{h}$ in non-urban sections. Table 9 presents the comparison results for the selected nine problems.

As it has been done in the base case, for the first four settings, the time limit for a single run of the SRDP and RDP-SOC heuristics is defined by the observed computation times of the classical RDP algorithm. Large $H$ and $S$ values in instances 5 and 6 require higher computation times. In order to complete 30 runs of the SRDP and RDP-SOC heuristics for the numerical experiments in each problem at a reasonable time, we have used a ratio of $1 / 2$. For example, the observed computation time of the classical RDP algorithm in Instance 1 - Setting 5 is $1122 \mathrm{~s}$. Therefore, the time limit for a single run of the SRDP and RDP-SOC heuristics is set as $1 / 2$ of this number, which is $561 \mathrm{~s}$.

Comparison results show that in all instances, except Instance 1 (UK_01) and Instance 7 (C201), the proposed heuristic provides the least-cost solutions. For the first and seventh instances, the least-cost solutions have been obtained from the classical RDP heuristic, i.e., Instance 1 under Setting 5: $€ 1203.53$ and Instance 7 under Settings 4,5,6: $€ 332.02$. The obtained least-cost solutions from the proposed heuristic are as follows: Instance 2 - Setting 6: €1218.70, Instance 3 - Setting 6: €1282.70, Instance 4 - Setting 6: $€ 1542.60$, Instance 5 - Setting 6: $€ 1300.40$, Instance 6 - Setting 6: $€ 268.12$, Instance 8 - Setting 6: €401.22, and Instance 9 - Setting 6: €394.10.

An overall comparison between the RDP-SOC and SRDP heuristics reveals that the proposed heuristic outperforms the SRDP in terms of the average total cost in 48 out of the 54 instance-setting pairs. Similarly, the proposed heuristic shows better cost performances in 40 instance-setting pairs compared to the classical RDP heuristic.

Among all instance-setting pairs, the resultant average cost of the proposed heuristic is $1 \%$ lower than that of the SRDP heuristic within the same computation time. The obtained average cost-benefit increases to $1.96 \%$ when the performance of the RDP-SOC heuristic is compared to that of the classical RDP heuristic. Considering huge budgets devoted to logistics management and small profit margins, these kinds of cost and/or emission savings could yield significant benefits in competitive advantage. Note that the proposed heuristic obtains these results within significantly shorter computation times, i.e., the average computation time of RDP-SOC in all instance-setting pairs $(755 \mathrm{~s})$ is almost half of that of the classical RDP $(1459 \mathrm{~s})$.

Figure 2 presents the average cost performances of the solution approaches in different settings. For settings 5 and 6 , all of the three heuristics are run with the same limit, that is why these setting are referred as $5 \mathrm{~A}$ and $6 \mathrm{~A}$. Note that in the previous analyses a ratio of $1 / 2$ has been used for the run times. In Table A.1, the reader can find the detailed results for performance assessment of the classical RDP, SRDP and RDP-SOC heuristics on the larger instances for settings 5 and 6 with the same time limit.

As can be observed from the figure, compared to the existing solution approaches, the proposed heuristic offers to have promising delivery plans in terms of the average cost in all settings that are run for the same time limit. 


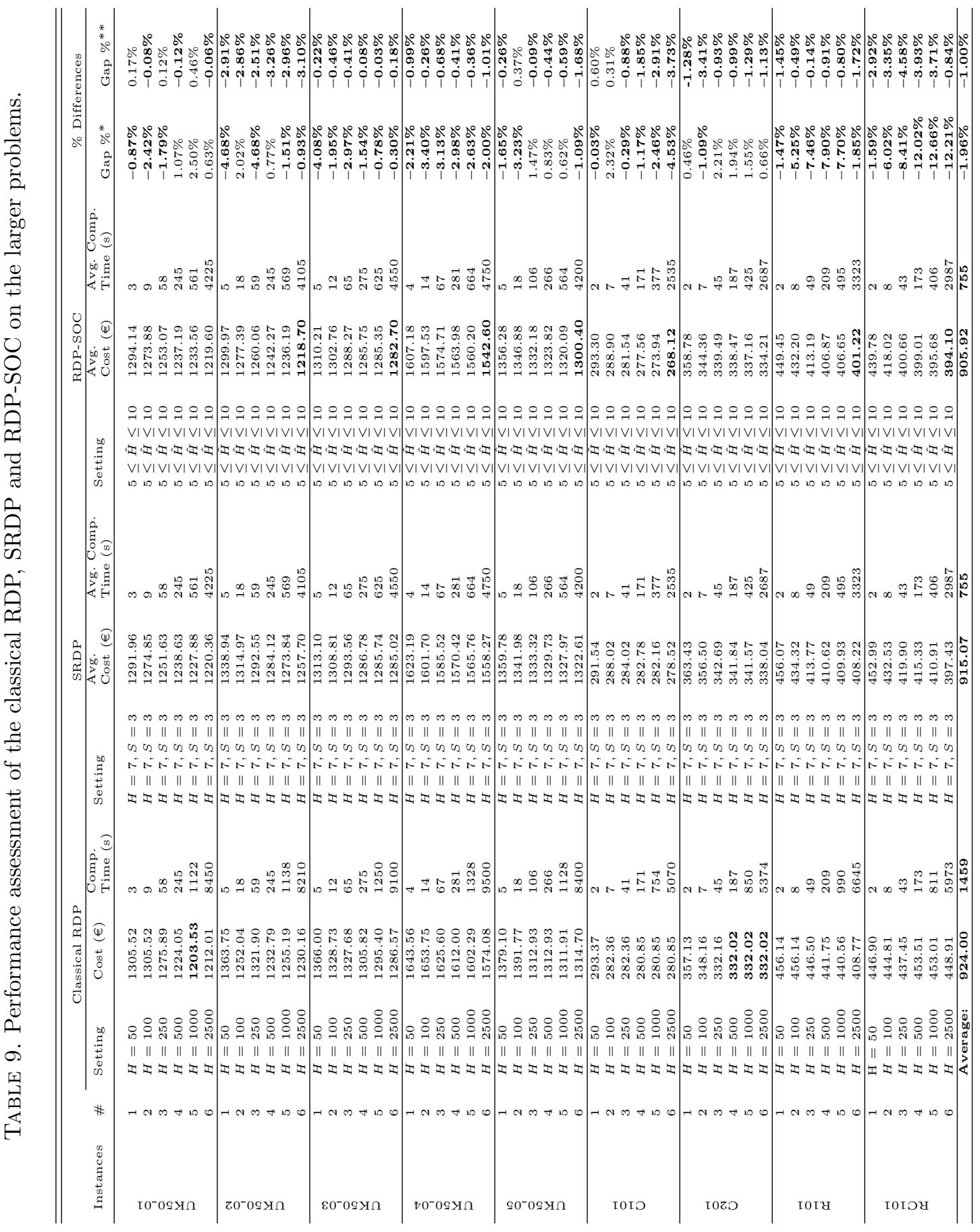




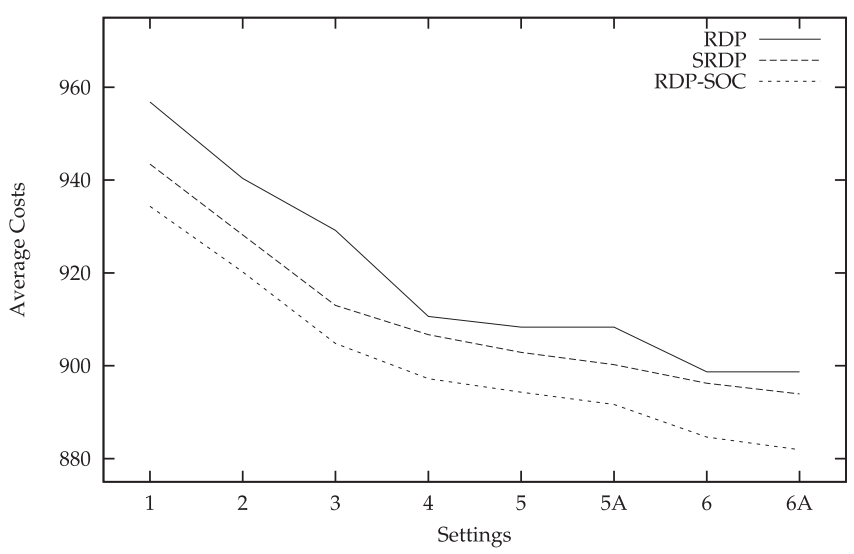

FIGURE 2. Average cost performances of the solution approaches in different settings.

TABLE 10. Representation of the resulting delivery plan for the base case when the same speed is assumed at every arc.

\begin{tabular}{|c|c|c|c|c|c|c|}
\hline Arc & Distance $(\mathrm{m})$ & Speed $(\mathrm{m} / \mathrm{s})$ & Travel time (s) & Service time (s) & Emissions (kg) & Fuel consumption (l) \\
\hline Depot-C5 & 75910 & 25 & 3036 & 1570 & 65.65 & 24.96 \\
\hline C5-C4 & 23080 & 25 & 923 & 692 & 19.96 & 7.59 \\
\hline @ $44-\mathrm{C} 13$ & 9820 & 25 & 393 & 972 & 8.49 & 3.23 \\
\hline C13-C14 & 34470 & 25 & 1379 & 820 & 29.81 & 11.34 \\
\hline$\stackrel{\mathrm{C} 14-\mathrm{C} 6}{ }$ & 20380 & 25 & 815 & 1606 & 17.63 & 6.70 \\
\hline$\vec{n}_{=}^{+} \mathrm{C} 6-\mathrm{C} 8$ & 8040 & 25 & 322 & 432 & 6.95 & 2.64 \\
\hline 爫 $\mathrm{C} 8-\mathrm{C} 10$ & 26180 & 25 & 1047 & 1496 & 22.64 & 8.61 \\
\hline C10-C12 & 7220 & 25 & 289 & 206 & 6.24 & 2.37 \\
\hline C12-Depot & 45090 & 25 & 1804 & 0 & 39.00 & 14.83 \\
\hline Depot-C11 & 24280 & 25 & 971 & 946 & 21.00 & 7.98 \\
\hline 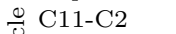 & 69411 & 25 & 2776 & 794 & 60.03 & 22.83 \\
\hline$\exists \mathrm{C} 2-\mathrm{C} 15$ & 31220 & 25 & 1249 & 1254 & 27.00 & 10.27 \\
\hline 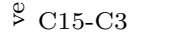 & 118401 & 25 & 4736 & 1386 & 102.40 & 38.94 \\
\hline C C3-C9 & 50070 & 25 & 2003 & 690 & 43.30 & 16.47 \\
\hline ¿ C9-C1 & 59100 & 25 & 2364 & 356 & 51.11 & 19.44 \\
\hline ๗ $\mathrm{C} 1-\mathrm{C} 7$ & 15280 & 25 & 611 & 1218 & 13.22 & 5.02 \\
\hline C7-Depot & 49450 & 25 & 1978 & 0 & 42.77 & 16.26 \\
\hline Total & 667402 & & 26696 & 14438 & 577.23 & 219.48 \\
\hline
\end{tabular}

Our computation analyses reveal the added values of the proposed RDP-SOC heuristic for the green routing problem. We acknowledge the fact that the proposed heuristic does not always guarantee a better solution than the ones which can be obtained from the classical RDP and SRDP heuristics. However, in most of the instance-setting pairs, the proposed heuristic outperforms the existing DP based solution approaches. The results demonstrate that RDP-SOC can be used as an alternative decision support tool to tackle large-sized VRPs confronted in sustainable logistics management.

\subsection{The effects of heterogeneity in arcs}

This subsection is devoted to analyse the effects of having heterogeneous arcs in terms of vehicle speed. The analyses here is conducted to show the possibility of a significant change in the results when there exist heterogeneous arcs in the logistics network, such that the routes and KPI values may considerably alter. 
TABLE 11. Results when the proposed route, which assumes the same speed at every arc, is implemented with the realistic vehicle speeds.

\begin{tabular}{|c|c|c|c|c|c|c|}
\hline Arc & Distance $(\mathrm{m})$ & Speed $(\mathrm{m} / \mathrm{s})$ & Travel time (s) & Service time (s) & Emissions (kg) & Fuel consumption (l) \\
\hline Depot-C5 & 75910 & 16.22 & 4680 & 1570 & 62.20 & 23.65 \\
\hline $\mathrm{C} 5-\mathrm{C} 4$ & 23080 & 13.74 & 1680 & 692 & 20.03 & 7.61 \\
\hline 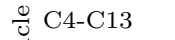 & 9820 & 9.63 & 1020 & 972 & 10.45 & 3.98 \\
\hline C13-C14 & 34470 & 17.95 & 1920 & 820 & 27.99 & 10.64 \\
\hline$>\mathrm{C} 14-\mathrm{C} 6$ & 20380 & 14.15 & 1440 & 1606 & 17.45 & 6.63 \\
\hline C6-C8 & 8040 & 12.18 & 660 & 432 & 7.44 & 2.83 \\
\hline 宅 $\mathrm{C} 8-\mathrm{C} 10$ & 26180 & 12.83 & 2040 & 1496 & 23.52 & 8.94 \\
\hline C10-C12 & 7220 & 10.03 & 720 & 206 & 7.50 & 2.85 \\
\hline C12-Depot & 45090 & 17.89 & 2520 & 0 & 36.61 & 13.92 \\
\hline Depot-C11 & 24280 & 13.49 & 1800 & 946 & 21.25 & 8.08 \\
\hline$\cong \mathrm{C} 11-\mathrm{C} 2$ & 69411 & 18.36 & 3780 & 794 & 56.41 & 21.45 \\
\hline$\exists \mathrm{C} 2-\mathrm{C} 15$ & 31220 & 15.77 & 1980 & 1254 & 25.74 & 9.79 \\
\hline$>\mathrm{C} 15-\mathrm{C} 3$ & 118401 & 18.97 & 6240 & 1386 & 96.49 & 36.69 \\
\hline च C3-C9 & 50070 & 21.96 & 2280 & 690 & 42.02 & 15.98 \\
\hline ¿ $\mathrm{C} 9-\mathrm{C} 1$ & 59100 & 21.89 & 2700 & 356 & 49.56 & 18.84 \\
\hline$\cong \mathrm{C} 1-\mathrm{C} 7$ & 15280 & 25.47 & 600 & 1218 & 13.26 & 5.04 \\
\hline C7-Depot & 49450 & 17.54 & 2820 & 0 & 40.17 & 15.27 \\
\hline Total & 667402 & & 38880 & 14438 & 558.11 & 212.21 \\
\hline
\end{tabular}

Let's assume that vehicles travel at a speed of $25 \mathrm{~m} / \mathrm{s}(90 \mathrm{~km} / \mathrm{h})$ at every arc in the base case. This means that vehicles have the chance to retain their speeds at each arc. The detailed representation of the resulting delivery plan obtained when the DP model assumes the same speed at every arc is presented in Table 10.

The estimated total logistics cost of this delivery plan presented in Table 10 is $€ 515.7$. Note that the provided delivery plan cannot be directly implemented in practice, as speed limits will not allow vehicles to have the same travel speeds in urban roads as in non-urban ones. We present the implementation of the proposed delivery plan, which assumes the same speed at every arc, with the realistic vehicle speeds in Table 11.

According to the results presented in Table 11, the total logistics cost of the delivery plan under realistic travel times is $€ 552.81$. This means that when the delivery plan obtained using the data set that ignores heterogeneity in arcs is implemented in practice, the resulting total logistics cost is more than expected. Note that this resulting total logistics cost is $0.5 \%$ higher than the one obtained when the realistic speeds are used (see Tab. 4).

Another key issue is that the DP model proposes a different delivery plan in terms of vehicle routes when the heterogeneity in arcs is ignored. As can be checked from Tables 5 and 10 or 11, although the resulting route for the first vehicle has not been altered, this is not the case for the second one.

\section{Conclusions}

Maintaining environmentally friendly operations in logistics management is a challenge for companies. This paper accordingly presents a decision support tool that can aid decision-making processes in operational level efficient logistics management. The introduced DP based solution approach can be used to have promising feasible delivery plans within short computational times for the larger problems. As distinct from the traditional approaches, the solution approach estimates fuel consumption based on travelled distance, vehicle speed and vehicle characteristics while constructing vehicle routes.

The added values of the RDP-SOC heuristic have been shown on a small-sized base case and five relatively larger problems. Performance comparisons of the proposed heuristic against other DP based recent solution approaches (the RDP and SRDP heuristics) reveal the effectiveness of the proposed approach in larger problems. According to the numerical analyses on heuristic performance, the proposed heuristic outperforms the SRDP in terms of the average total cost in 48 out of the 54 instance-setting pairs. Similarly, the proposed heuristic 
shows better cost performances in 22 instance-setting pairs compared to the classical RDP heuristic within significantly shorter computation times.

Additional analysis to reveal the effects of heterogeneity in arcs shows that when heterogeneity is ignored, the resulting delivery plan may change and has a higher logistics cost.

These results on small and large-sized instances confirm that the proposed solution approach can be used as an alternative decision support tool to tackle large-sized VRPs. It is worth mentioning that the introduced DP based solution approach is also highly flexible in terms of incorporating other potential problem-specific constraints such as uncertainty in travel or service times, the existence of customer time windows or having time-dependent travel times in arcs due to traffic congestion. Future studies on routing problems might focus on finding out better ways for state-space exploration in the DP algorithm and incorporate the aforementioned dimensions. We believe that this research has the potential to lead the way for further enhancements.

\section{Appendix A.}

TABLE A.1. Performance assessment of the classical RDP. SRDP and RDP-SOC on the larger instances for settings 5 and 6 with the same time limit.

\begin{tabular}{|c|c|c|c|c|c|c|c|c|c|c|c|c|}
\hline \multirow{2}{*}{\multicolumn{2}{|c|}{$\#$}} & \multicolumn{3}{|c|}{ Classical RDP } & \multicolumn{3}{|c|}{ SRDP } & \multicolumn{3}{|c|}{ RDP-SOC } & \multicolumn{2}{|c|}{$\%$ Differences } \\
\hline & & Setting & $\begin{array}{l}\begin{array}{l}\text { Cost } \\
\text { (euro) }\end{array} \\
\end{array}$ & $\begin{array}{l}\text { Comp. } \\
\text { Time (s) }\end{array}$ & $\begin{array}{l}\text { Setting } \\
\text { Cost (euro) }\end{array}$ & $\begin{array}{l}\text { Avg. } \\
\text { Time (s) }\end{array}$ & Avg. Comp. & Setting & $\begin{array}{l}\text { Avg. Cost } \\
\text { (euro) }\end{array}$ & $\begin{array}{l}\text { Avg. Comp. } \\
\text { Time (s) }\end{array}$ & Gap \%* & Gap $\%^{* *}$ \\
\hline $\begin{array}{l}-1 \\
0 \\
0 \\
0 \\
10 \\
1 \\
0\end{array}$ & $\begin{array}{l}5 \mathrm{~A} \\
6 \mathrm{~A} \\
\end{array}$ & $\begin{aligned} \mathrm{H} & =1000 \\
H & =2500\end{aligned}$ & $\begin{array}{l}\mathbf{1 2 0 3 . 5 3} \\
1212.01\end{array}$ & $\begin{array}{l}1122 \\
8450\end{array}$ & $\begin{array}{l}H=7, S=3 \\
H=7, S=3\end{array}$ & $\begin{array}{l}1225.46 \\
1219.60\end{array}$ & $\begin{array}{l}1122 \\
8450\end{array}$ & $\begin{array}{l}5 \leq \hat{H} \leq 10 \\
5 \leq \hat{H} \leq 10\end{array}$ & $\begin{array}{l}1230.65 \\
1218.60\end{array}$ & $\begin{array}{l}1122 \\
8450\end{array}$ & $\begin{array}{l}2.25 \% \\
0.54 \%\end{array}$ & $\begin{array}{l}0.42 \% \\
-0.08 \%\end{array}$ \\
\hline 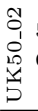 & $\begin{array}{l}5 \mathrm{~A} \\
6 \mathrm{~A} \\
\end{array}$ & $\begin{aligned} H & =1000 \\
H & =2500\end{aligned}$ & $\begin{array}{l}1255.19 \\
1230.16\end{array}$ & $\begin{array}{l}1138 \\
8210\end{array}$ & $\begin{array}{l}H=7, S=3 \\
H=7, S=3\end{array}$ & $\begin{array}{l}1270.43 \\
1255.62\end{array}$ & $\begin{array}{l}1138 \\
8210\end{array}$ & $\begin{array}{l}5 \leq \hat{H} \leq 10 \\
5 \leq \hat{H} \leq 10\end{array}$ & $\begin{array}{l}1233.20 \\
\mathbf{1 2 1 5 . 7 1}\end{array}$ & $\begin{array}{l}1138 \\
8210\end{array}$ & $\begin{array}{l}-1.75 \% \\
-1.17 \%\end{array}$ & $\begin{array}{l}-2.93 \% \\
-3.18 \%\end{array}$ \\
\hline $\begin{array}{l}m \\
0 \\
0 \\
0 \\
01 \\
1 \\
\vdots \\
0\end{array}$ & $\begin{array}{l}5 \mathrm{~A} \\
6 \mathrm{~A} \\
\end{array}$ & $\begin{aligned} \mathrm{H} & =1000 \\
H & =2500\end{aligned}$ & $\begin{array}{l}1295.40 \\
1286.57\end{array}$ & $\begin{array}{l}1250 \\
9100\end{array}$ & $\begin{array}{l}H=7, S=3 \\
H=7, S=3\end{array}$ & $\begin{array}{l}1284.81 \\
1283.02\end{array}$ & $\begin{array}{l}1250 \\
9100\end{array}$ & $\begin{array}{l}5 \leq \hat{H} \leq 10 \\
5 \leq \hat{H} \leq 10\end{array}$ & $\begin{array}{l}1284.70 \\
\mathbf{1 2 7 9 . 6 5}\end{array}$ & $\begin{array}{l}1250 \\
9100\end{array}$ & $\begin{array}{l}-0.83 \% \\
-0.54 \%\end{array}$ & $\begin{array}{l}-0.01 \% \\
-0.26 \%\end{array}$ \\
\hline $\begin{array}{l}3 \\
0 \\
0 \\
0 \\
10 \\
1 \\
5 \\
5\end{array}$ & $\begin{array}{l}5 \mathrm{~A} \\
6 \mathrm{~A} \\
\end{array}$ & $\begin{aligned} H & =1000 \\
H & =2500\end{aligned}$ & $\begin{array}{l}1602.29 \\
1574.08\end{array}$ & $\begin{array}{l}1328 \\
9500\end{array}$ & $\begin{array}{l}H=7, S=3 \\
H=7, S=3\end{array}$ & $\begin{array}{l}1561.66 \\
1553.69\end{array}$ & $\begin{array}{l}1328 \\
9500\end{array}$ & $\begin{array}{l}5 \leq \hat{H} \leq 10 \\
5 \leq \hat{H} \leq 10\end{array}$ & $\begin{array}{l}1548.25 \\
\mathbf{1 5 3 2 . 4 1}\end{array}$ & $\begin{array}{l}1328 \\
9500\end{array}$ & $\begin{array}{l}-3.37 \% \\
-2.65 \%\end{array}$ & $\begin{array}{l}-0.86 \% \\
-1.37 \%\end{array}$ \\
\hline $\begin{array}{l}20 \\
0 \\
1 \\
0 \\
10 \\
1 \\
1 \\
0 \\
\end{array}$ & $\begin{array}{l}5 \mathrm{~A} \\
6 \mathrm{~A} \\
\end{array}$ & $\begin{aligned} \mathrm{H} & =1000 \\
H & =2500\end{aligned}$ & $\begin{array}{l}1311.91 \\
1314.70\end{array}$ & $\begin{array}{l}1128 \\
8400\end{array}$ & $\begin{array}{l}H=7, S=3 \\
H=7, S=3\end{array}$ & $\begin{array}{l}1325.88 \\
1320.23\end{array}$ & $\begin{array}{l}1128 \\
8400\end{array}$ & $\begin{array}{l}5 \leq \hat{H} \leq 10 \\
5 \leq \hat{H} \leq 10\end{array}$ & $\begin{array}{l}1318.17 \\
\mathbf{1 2 9 6 . 4 3}\end{array}$ & $\begin{array}{l}1128 \\
8400\end{array}$ & $\begin{array}{l}0.48 \% \\
-\mathbf{1 . 3 9 \%}\end{array}$ & $\begin{array}{l}-0.58 \% \\
-1.80 \%\end{array}$ \\
\hline $\begin{array}{l}-1 \\
0 \\
0 \\
0\end{array}$ & $\begin{array}{l}5 \mathrm{~A} \\
6 \mathrm{~A}\end{array}$ & $\begin{aligned} \mathrm{H} & =1000 \\
H & =2500\end{aligned}$ & $\begin{array}{l}280.85 \\
280.85\end{array}$ & $\begin{array}{l}754 \\
5070\end{array}$ & $\begin{array}{l}H=7, S=3 \\
H=7, S=3\end{array}$ & $\begin{array}{l}280.64 \\
274.51\end{array}$ & $\begin{array}{l}754 \\
5070\end{array}$ & $\begin{array}{l}5 \leq \hat{H} \leq 10 \\
5 \leq \hat{H} \leq 10\end{array}$ & $\begin{array}{l}272.99 \\
\mathbf{2 6 7 . 2 0}\end{array}$ & $\begin{array}{l}754 \\
5070\end{array}$ & $\begin{array}{l}-2.80 \% \\
-4.86 \%\end{array}$ & $\begin{array}{l}-2.73 \% \\
-2.66 \%\end{array}$ \\
\hline $\begin{array}{c}-1 \\
\text { Uे }\end{array}$ & $\begin{array}{l}5 \mathrm{~A} \\
6 \mathrm{~A}\end{array}$ & $\begin{aligned} \mathrm{H} & =1000 \\
H & =2500\end{aligned}$ & $\begin{array}{l}332.02 \\
332.02\end{array}$ & $\begin{array}{l}850 \\
5374\end{array}$ & $\begin{array}{l}H=7, S=3 \\
H=7, S=3\end{array}$ & $\begin{array}{l}341.25 \\
337.50\end{array}$ & $\begin{array}{l}850 \\
5374\end{array}$ & $\begin{array}{l}5 \leq \hat{H} \leq 10 \\
5 \leq \hat{H} \leq 10\end{array}$ & $\begin{array}{l}336.28 \\
332.56\end{array}$ & $\begin{array}{l}850 \\
5374\end{array}$ & $\begin{array}{l}1.28 \% \\
0.16 \%\end{array}$ & $\begin{array}{l}-1.46 \% \\
-1.46 \%\end{array}$ \\
\hline $\begin{array}{l}\overrightarrow{1} \\
\vec{\sim} \\
\vec{\sim}\end{array}$ & $\begin{array}{l}5 \mathrm{~A} \\
6 \mathrm{~A}\end{array}$ & $\begin{aligned} H & =1000 \\
H & =2500\end{aligned}$ & $\begin{array}{l}440.56 \\
408.77\end{array}$ & $\begin{array}{l}990 \\
6645\end{array}$ & $\begin{array}{l}H=7, S=3 \\
H=7, S=3\end{array}$ & $\begin{array}{l}408.56 \\
406.87\end{array}$ & $\begin{array}{l}990 \\
6645\end{array}$ & $\begin{array}{l}5 \leq \hat{H} \leq 10 \\
5 \leq \hat{H} \leq 10\end{array}$ & $\begin{array}{l}405.23 \\
\mathbf{4 0 1 . 1 2}\end{array}$ & $\begin{array}{l}990 \\
6645\end{array}$ & $\begin{array}{l}-8.02 \% \\
-1.87 \%\end{array}$ & $\begin{array}{l}-0.82 \% \\
-1.41 \%\end{array}$ \\
\hline $\begin{array}{l}-1 \\
0 \\
ت \\
0 \\
\end{array}$ & $\begin{array}{l}5 \mathrm{~A} \\
6 \mathrm{~A}\end{array}$ & $\begin{aligned} \mathrm{H} & =1000 \\
H & =2500\end{aligned}$ & $\begin{array}{l}453.01 \\
448.91\end{array}$ & $\begin{array}{l}811 \\
5973\end{array}$ & $\begin{array}{l}H=7, S=3 \\
H=7, S=3\end{array}$ & $\begin{array}{l}403.35 \\
394.40\end{array}$ & $\begin{array}{l}811 \\
5973\end{array}$ & $\begin{array}{l}5 \leq \hat{H} \leq 10 \\
5 \leq \hat{H} \leq 10\end{array}$ & $\begin{array}{l}395.50 \\
\mathbf{3 9 3 . 5 2}\end{array}$ & $\begin{array}{l}811 \\
5973\end{array}$ & $\begin{array}{l}-12.70 \% \\
-12.34 \%\end{array}$ & $\begin{array}{l}-1.95 \% \\
-0.22 \%\end{array}$ \\
\hline & & Average: & 903.49 & 4227 & & 897.08 & 4227 & & 886.79 & 4227 & $-1.85 \%$ & $-1.15 \%$ \\
\hline
\end{tabular}

Notes. ${ }^{*}$ The percentage gap between average costs obtained from the RDP and RDP-SOC heuristics. ${ }^{* *}$ The percentage gap between average costs obtained from the SRDP and RDP-SOC heuristics. Bold values demonstrate the relatively better results. 


\section{REFERENCES}

[1] P. Ahi, and C. Searcy, A comparative literature analysis of definitions for green and sustainable supply chain management. J. Cleaner Prod. 52 (2013) 329-341.

[2] P. Alvarez, I. Lerga, A. Serrano-Hernandez and J. Faulin, The impact of traffic congestion when optimising delivery routes in real time. A case study in spain. Int. J. Logistics Res. App. 21 (2018) 529-541.

[3] A. Bastas and K. Liyanage, Sustainable supply chain quality management: a systematic review. J. Cleaner Prod. 181 (2018) $726-744$.

[4] T. Bektaş and G. Laporte, The pollution-routing problem. Transp. Res. Part B Methodological 45 (2011) 1232-1250.

[5] T. Bektaş, E. Demir and G. Laporte, Green vehicle routing. In: Green Transportation Logistics, Vol. 226 of International Series in Operations Research \&S Management Science. Springer, Cham (2016) 243-265.

[6] T. Bektaş, J.F. Ehmke, H.N. Psaraftis and J. Puchinger, The role of operational research in green freight transportation. Eur. J. Oper. Res. 274 (2019) 807-823.

[7] R. Bellman, Dynamic programming treatment of the traveling salesman problem. J. ACM 9 (1962) 61-63.

[8] P.G. Boulter, T.J. Barlow and I.S. McCrae, Emission factors 2009: report 3 - exhaust emission factors for road vehicles in the United Kingdom. Technical Report. Published project report PPR356 by TRL limited (2009).

[9] M. Bravo, L.P. Rojas and V. Parada, An evolutionary algorithm for the multi-objective pick-up and delivery pollution-routing problem. Int. Trans. Oper. Res. 26 (2019) 302-317.

[10] W.R. Cherif-Khettaf, M.H. Rachid, C. Bloch and P. Chatonnay, New notation and classification scheme for vehicle routing problems. RAIRO:OR 49 (2015) 161-194.

[11] M. Çimen and M. Soysal, Time-dependent green vehicle routing problem with stochastic vehicle speeds: an approximate dynamic programming algorithm. Transp. Res. Part D: Transp. Environ. 54 (2017) 82-98.

[12] L.C. Coelho, J. Renaud and G. Laporte, Road-based goods transportation: a survey of real-world logistics applications from 2000 to 2015. INFOR: Info. Syst. Oper. Res. 54 (2016) 79-96.

[13] D. Coley, M. Howard and M. Winter, Local food, food miles and carbon emissions: a comparison of farm shop and mass distribution approaches. Food Policy 34 (2009) 150-155.

[14] DEFRA, Guidelines to Defra's GHG conversion factors for company reporting - Annexes updated June 2007. Technical Report. Department for Environment, Food and Rural Affairs (2007).

[15] E. Demir, T. Bektaş and G. Laporte, A review of recent research on green road freight transportation. Eur. J. Oper. Res. 237 (2014) $775-793$.

[16] R. Dubey, A. Gunasekaran, T. Papadopoulos, S.J. Childe, K. Shibin and S.F. Wamba, Sustainable supply chain management: framework and further research directions. J. Cleaner Prod. 142 (2017) 1119-1130.

[17] R. Eglese and T. Bektaş, Green vehicle routing. Veh. Routing: Prob. Methods App. 18 (2014) 437-458.

[18] A. Franceschetti, D. Honhon, T. Van Woensel, T. Bektaş and G. Laporte, The time-dependent pollution-routing problem. Transp. Res. Part B: Methodological 56 (2013) 265-293.

[19] A. Franceschetti, E. Demir, D. Honhon, T. Van Woensel, G. Laporte and M. Stobbe, A metaheuristic for the time-dependent pollution-routing problem. Eur. J. Oper. Res. 259 (2017) 972-991.

[20] B. Funke, T. Grünert and S. Irnich, Local search for vehicle routing and scheduling problems: review and conceptual integration. J. Heuristics 11 (2005) 267-306.

[21] M. Gajanand and T. Narendran, Green route planning to reduce the environmental impact of distribution. Int. J. Logistics Res. App. 16 (2013) 410-432.

[22] M. Gan, X. Liu, S. Chen, Y. Yan and D. Li, The identification of truck-related greenhouse gas emissions and critical impact factors in an urban logistics network. J. Cleaner Prod. 178 (2018) 561-571.

[23] A. Goel, Vehicle scheduling and routing with drivers' working hours. Transp. Sci. 43 (2009) 17-26.

[24] J. Gromicho, J.J. van Hoorn, A.L. Kok and J.M.J. Schutten, The flexibility of restricted dynamic programming for the VRP. Beta Working Pap. Ser. 266 (2008) 1-20.

[25] J. Gromicho, J.J. van Hoorn, A.L. Kok and J.M.J. Schutten, Restricted dynamic programming: a flexible framework for solving realistic VRPs. Comput. Oper. Res. 39 (2012) 902-909.

[26] M. Held and R.M. Karp, A dynamic programming approach to sequencing problems. J. SIAM 10 (1962) $196-210$.

[27] I. Kara, B. Kara and M. Yetis, Energy minimizing vehicle routing problem, edited by A. Dress, Y. Xu and B. Zhu. In: Vol. 4616 of Lecture Notes in Computer Science Combinatorial Optimization and Applications. Springer, Berlin-Heidelberg (2007) 62-71.

[28] A.L. Kok, C.M. Meyer, H. Kopfer and J.M.J. Schutten, A dynamic programming heuristic for the vehicle routing problem with time windows and european community social legislation. Transp. Sci. 44 (2010) 442-454.

[29] A.L. Kok, E.W. Hans and J.M.J. Schutten, Vehicle routing under time-dependent travel times: the impact of congestion avoidance. Comput. Oper. Res. 39 (2012) 910-918.

[30] G. Laporte, H. Mercure and Y. Nobert, An exact algorithm for the asymmetrical capacitated vehicle-routing problem. NETWORKS 16 (1986) 33-46.

[31] G. Laporte, F. Louveaux and L. van Hamme, An integer L-shaped algorithm for the capacitated vehicle routing problem with stochastic demands. Oper. Res. 50 (2002) 415-423.

[32] C. Lin, K.L. Choy, G.T.S. Ho, S.H. Chung and H.Y. Lam, Survey of green vehicle routing problem: past and future trends. Expert Syst. App. 41 (2014) 1118-1138. 
[33] S. Majidi, S.M. Hosseini-Motlagh, S. Yaghoubi and A. Jokar, Fuzzy green vehicle routing problem with simultaneous pickupdelivery and time windows. RAIRO:OR 51 (2017) 1151-1176.

[34] Y. Niu, Z. Yang, P. Chen and J. Xiao, Optimizing the green open vehicle routing problem with time windows by minimizing comprehensive routing cost. J. Cleaner Prod. 171 (2018) 962-971.

[35] E. Pérez-Bernabeu, A.A. Juan, J. Faulin and B.B. Barrios, Horizontal cooperation in road transportation: a case illustrating savings in distances and greenhouse gas emissions. Int. Trans. Oper. Res. 22 (2015) 585-606.

[36] K.N. Reddy, A. Kumar and E.E. Ballantyne, A three-phase heuristic approach for reverse logistics network design incorporating carbon footprint. Int. J. Prod. Res. 57 (2019) 6090-6114.

[37] S. Rogerson, Influence of freight transport purchasing processes on logistical variables related to $\mathrm{CO}_{2}$ emissions: a case study in Sweden. Int. J. Logistics Res. App. 20 (2017) 604-623.

[38] M. Salehi, M. Jalalian and M.M.V. Siar, Green transportation scheduling with speed control: trade-off between total transportation cost and carbon emission. Comput. Ind. Eng. 113 (2017) 392-404.

[39] I. Sbai, S. Krichen and O. Limam, Two meta-heuristics for solving the capacitated vehicle routing problem: the case of the tunisian post office. Oper. Res. (2020) 1-43.

[40] M.M. Solomon, Algorithms for the vehicle routing and scheduling problems with time window constraints. Oper. Res. 35 (1987) 254-265.

[41] M. Soysal, Decision support modeling for sustainable food logistics management, Ph.D. thesis. Wageningen University (2015).

[42] M. Soysal and M. Çimen, A simulation based restricted dynamic programming approach for the green time dependent vehicle routing problem. Comput. Oper. Res. 88 (2017) 297-305.

[43] M. Soysal, M. Çimen, S. Belbağ and E. Toğrul, A review on sustainable inventory routing. Comput. Ind. Eng. 132 (2019) 395-411.

[44] M. Soysal, M. Çimen, M. Ömürgönülşen and S. Belbağ, Performance comparison of two recent heuristics for green time dependent vehicle routing problem. Int. J. Bus. Anal. (IJBAN) 6 (2019) 1-11.

[45] F. Tao, T. Fan and K.K. Lai, Optimal inventory control policy and supply chain coordination problem with carbon footprint constraints. Int. Trans. Oper. Res. 25 (2018) 1831-1853.

[46] S. Validi, A. Bhattacharya and P. Byrne, Integrated low-carbon distribution system for the demand side of a product distribution supply chain: a doe-guided MOPSO optimiser-based solution approach. Int. J. Prod. Res. 52 (2014) $3074-3096$.

[47] Y. Xiao, X. Zuo, J. Huang, A. Konak and Y. Xu, The continuous pollution routing problem. Appl. Math. Comput. 387 (2020) 125072 .

[48] L. Zhu and D. Hu, Study on the vehicle routing problem considering congestion and emission factors. Int. J. Prod. Res. 57 (2019) 6115-6129. 